\title{
LA LEY RICARTE SOTO: NECESARIA PERO POLÉMICA
}

\author{
The Ricarte Soto Act: NeCESSARy bUt POlemic
}

Es efectivo que la Ley Ricarte Soto (R.S.) se complicó en exceso al extenderse a la regulación de la investigación clínica con seres humanos, asunto tratado en la Ley 20.120 de 2006 y su posterior reglamentación en el Decreto 114. Pero algo debía ser dicho, por cuanto las terapias de enfermedades de alto costo y de escasa prevalencia están, por lo general, en etapa de estudio clínico pre-registro: no son terapias de "efectividad probada" como la Ley R.S. pretende exigir para financiarlas, ni son experimentos porque su objetivo, más que indagar, es encontrar terapéuticas urgentemente necesarias que, de ser efectivas, serán de alto costo y/o enfocadas sobre enfermedades raras. Son, por ende, terapias experimentales, cuya regulación ética es más específica porque se refiere a pacientes críticamente enfermos, y porque tienen una trayectoria que se distingue de las investigaciones clínicas generales que recorren el camino del laboratorio, el animal, las fases I a III. Las terapias experimentales, por su urgencia, se aplican en fase I y prescinden del uso de placebos.

Sorprende penosamente que investigadores y académicos dedicados a la bioética protesten por cláusulas que protegen al paciente investigado al asegurarles acceso privilegiado, por todo el tiempo que sea médicamente necesario tras el término del estudio, a terapias que resulten beneficiosas, y que además garanticen ampliamente que el paciente recibirá tratamiento y compensación por daños resultantes de la investigación.

La bioética tiene por objetivo proteger a los desaventajados -pacientes, sujetos de investigación, marginados y discriminados por edad, sexo, limitaciones corporales-. No es su tarea velar por los intereses corporativos de la más potente y lucrativa empresa transnacional como es la farmacéutica. Los costos de albergar médicamente a los pacientes que participan en establecer una medicación efectiva y que producirá ingresos multimillonarios, no reducen el entusiasmo investigativo-mercantil, como lo prueba el excelente negocio de los medicamentos antirretrovirales, las quimioterapias, los antiangiogénicos. Los bioeticistas e investigadores que desarrollan una campaña de alerta por la supuesta paralización de la investigación biomédi-

Miguel Kottow Editor Revista Chilena de Salud Pública mhkottow@gmail.com ca que produciría la Ley R.S., y que privilegian y fomentan una reducción de la protección de probandos por defender otros intereses de orden corporativo, han extraviado el rumbo de la responsabilidad ética de la investigación como un servicio a la sociedad, y la tarea de la bioética respectiva. 
La bioética latinoamericana recuerda con nostalgia el Artículo 30 de la Declaración de Helsinki del año 2000 (quinta versión modificada del original de 1964): “Al concluir el estudio, todo paciente que hubiese ingresado a [ese] estudio deberá tener asegurado el acceso a los mejores métodos profilácticos, diagnósticos o terapéuticos identificados por el estudio". La más reciente versión (Fortaleza, 2013) señala: “[A]ntes del ensayo clínico, los auspiciadores, investigadores y los gobiernos de los países anfitriones deben prever el acceso post ensayo a todos los participantes que todavía necesitan una intervención que ha sido identificada como beneficiosa en el ensayo. Esta información también se debe proporcionar a los participantes durante el proceso del consentimiento informado".

Así lo quiere la Ley Ricarte Soto, pero investigadores y patrocinantes se niegan a hacer lo correcto, amenazan con secar la investigación en Chile, prefieren ahorrar a costa de los enfermos. ¿Es aventurado decir que los conceptos están desanclados, que urge rescatarlos de la deriva? 